\title{
Analisis Pelaksanaan Sistem Dan Prosedur Akuntansi Pengeluaran Kas Pada Dinas Kesehatan Kota Manado
}

\author{
Oleh: \\ Ray Risiano Imanuel Laotongan ${ }^{1}$ \\ David P. E. Saerang ${ }^{2}$ \\ Heince R. N. Wokas ${ }^{3}$
}

\author{
Fakultas Ekonomi Dan Bisnis \\ Universitas Sam Ratulangi Manado \\ Email: ${ }^{1}$ raylaotongan@gmail.com
}

\begin{abstract}
Cash expenditures is a component that is very important resource in the implementation of development programs that have been planned by the government. In government department cash expenditure have system and procedure that manage/control the cash expenditure. The purpose of this research was to analyze if the implementation of systems and procedures for cash expenses appropriate with the existing rule. Objects of this research is on the Department of Public Health of Manado City. Anlysis method used is descriptive analysis method that aims to make a picture of systematic, factual, and accruals of the facts, by comparing between system and expenses procedures performed by the Department of Public Health with the concepts of cash expenses system.The result of this research about system and procedure at the Department of Public Health of Manado City, cash expenditure procedure was appropriate with the existing rules but in the implementation still have a shortage that there is no authorization through PPK-SKPD.
\end{abstract}

Keywords: analysis, implementation, systems, procedures cash expenditure.

\section{PENDAHULUAN}

Indonesia merupakan negara kepulauan yang memiliki wilayah yang luas dan terdiri dari 34 provinsi. Setiap provinsi memiliki suatu sistem pemerintahannya sendiri dan memiliki otonomi daerahnya masing-masing. Menurut Istianto (2009) otonomi daerah merupakan hak dan wewenang untuk mengatur dan mengurus rumah tangga daerah. Menurut wikipedia yang dimaksud daerah otonom adalah daerah dalam suatu negara yang memiliki kekuasaan otonom atau kebebasan dari pemerintah diluar daerah tersebut. Hal ini memberi akibat pada pengaturan sistem keuangan pemerintahan di daerah. Otonomi daerah menuntut pemerintahan daerah untuk lebih memberikan pelayanan publik yang didasarkan asas-asas pelayanan publik yang meliputi transparansi, akuntabilitas, kondisional, partisipatif, kesamaan hak, serta keseimbangan hak dan kewajiban demi tercapainya good governance.

Perubahan manajemen keuangan daerah di era otonomi daerah ditandai dengan perubahan yang sangat mendasar, mulai dari sistem penganggarannya, perbendaharaan sampai kepada pertanggungjawaban laporan keuangannya. Pertanggungjawaban laporan keuangan daerah sebelum bergulirnya otonomi daerah harus disiapkan oleh pemerintahan hanya berupa laporan perhitungan Anggaran dan Nota Perhitungan dan sistem yang 
digunakan untuk menghasilkan laporan tersebut adalah MAKUDA (Manual Administrasi Keuangan Daerah) yang diberlakukan sejak tahun 1981.

Pengelolaan keuangan daerah merupakan salah satu bagian yang mengalami perubahan mendasar dengan ditetapkannya Undang-Undang (UU) No. 32 Tahun 2004 tentang Pemerintahan Daerah dan UU No. 33 Tahun 2004 tentang Perimbangan Keuangan Pemerintah Pusat dan Pemerintah Daerah. Kedua UU tersebut telah memberikan kewenangan yang dimaksud diantaranya adalah keleluasaan dalam mobilisasi sumber dana, menentukan arah, tujuan dan target penggunaan anggaran.

Sesuai dengan Peraturan Menteri Dalam Negeri (Permendagri) No. 59 Tahun 2007 tentang perubahan atas Permendagri No. 13 Tahun 2006 tentang Pedoman pengelolaan Keuangan Daerah, bahwa prosedur akuntansi yang diterapkan dalam lingkungan pemerintahan daerah meliputi prosedur akuntansi Penerimaan Kas, Pengeluaran Kas, Akuntansi Aset dan Akuntansi Selain Kas.

Pengeluaran kas merupakan komponen sumber daya yang sangat penting di dalam melaksanakan program pembangunan yang telah direncanakan oleh pemerintah. Kas diakui sebesar nilai nominal dari uang tunai atau yang dapat dipersamakan dengan uang tunai, serta rekening giro di bank yang tidak dibatasi penggunaannya. Perubahan kas dipengaruhi oleh pengeluaran kas. Pengeluaran kas meliputi transaksi-transaksi yang mengakibatkan berkurangnya saldo kas tunai dan atau rekening bank milik entitas pemerintah daerah. Sebagai organisasi sektor publik yang bergerak di bidang kesehatan masyarakat, Dinas Kesehatan Kota Manado menerapkan mekanisme pencatatan dan pengelolaan keuangan yang juga membahas tentang pengeluaran kas.

Berdasarkan uraian latar belakang diatas, maka masalah yang dapat dikemukakan dalam penelitian ini yaitu "bagaimana pelaksanaan sistem dan prosedur pengeluaran kas pada Dinas Kesehatan Kota Manado?"

Tujuan penelitian ini adalah untuk mengetahui pelaksanaan sistem dan prosedur pengeluaran kas dan menganalisis apakah pelaksanaan sistem dan prosedur pengeluaran kas pada Dinas Kesehatan Kota Manado sudah sesuai dengan peraturan yang berlaku.

\section{TINJAUAN PUSTAKA}

Menurut Bastian (2009:15), akuntansi sektor publik adalah mekanisme teknik dan analisis akuntansi yang diterapkan pada pengelolaan dana masyarakat di Lembaga Tinggi Negara dan departemen-departemen di bawahnya, pemerintah daerah, BUMN, BUMD, LSM dan yayasan sosial, maupun pada proyek-proyek kerja sama sektor publik dan swasta.

Menurut PP No. 58 Tahun 2005 tentang pengelolaan keuangan daerah, keuangan daerah adalah semua hak dan kewajiban dalam rangka penyelenggaraan pemerintah daerah yang dapat dinilai dengan uang termasuk didalamnya segala bentuk kekayaan yang berhubungan dengan hak dan kewajiban daerah tersebut. Sesuai dengan Permendagri No. 59 Tahun 2007, yang merupakan perubahan permendagri Nomor 13 Tahun 2006 tentang pedoman pengelolaan keuangan daerah, pengeloolaan keuangan daerah tak lagi bertumpu atau mengandalkan bagian keuangan sekretariat daerah kabupaten/kota saja, tapi dalam permendagri itu pun disebutkan. Setiap SKPD kini wajib menyusun dan melaporkan posisi keuangannya, yang kemudian dikoordinasikan dengan bagian keuangan.

Kas adalah harta yang dapat digunakan untuk membayar kegiatan operasional perusahaan atau dapat digunakan untuk membayar kewajiban saat ini. Wujud dari kas dapat berupa uang kertas/logam, simpanan bank yang sewaktu-waktu dapat ditarik, dana kas kecil, cek bilyet giro dan sebagainya. Item yang tidak dapat dikatakan kas adalah cek mundur, cek yang tidak cukup dananya/not sufficient fund (NSF) check, saldo dana yang kegunaanya dibatasi, saldo rekening Koran yang diblokir (Yahya, 2009). 
Sistem pengeluaran kas adalah serangkaian proses mulai pencatatan, penggolongan dan peringkasan transaksi dan / atau kejadian keuangan serta pelaporan keuangan dalam rangka pertanggungjawaban pelaksanaan APBD yang berkenaan dengan pengeluaran kas pada SKPKD dan / atau pada SKPD yang dapat dilaksanakan secara manual maupun terkomputerisasi.

Menurut Halim (2008:80), prosedur akuntansi pengeluaran kas meliputi serangkaian proses, baik manual maupun terkomputerisasi mulai dari pencatatan, penggolongan dan peringkasan transaksi dasar atau kejadian keuangan, hingga pelaporan keuangan dalam rangka pertanggungjawaban pelaksanaan APBD yang berkaitan dengan pengeluaran kas pada SKPD dan/atau SKPKD.

Permendagri No. 55 Tahun 2008 tentang tata cara penatausahaan dan penyusunan laporan pertanggungjawaban bendahara serta penyampaiannya menyatakan bahwa bendahara pengeluaran PPKD menyampaikan pertanggungjawaban atas pengelolaan fungsi kebendaharaan yang berada dalam tanggung jawabnya setiap tanggal 10 bulan berikutnya. Pertanggung jawaban tersebut disampaikan kepada PPKD. Dalam melakukan pertanggungjawaban tersebut, dokumen yang disampaikan adalah Surat Petanggungjawaban (SPJ).

1. Revalia (2011) dengan judul Analisis Pelaksanaan Sistem dan Prosedur Penerimaan dan Pengeluaran Kas pada Dinas Pendapatan Pengelolaan Keuangan dan Aset Daerah Kota Kotamobagu. Tujuannya untuk mengetahui efektivitas sistem dan prosedur penerimaan dan pengeluaran kas pada dinas pendapatan pengelolaan keuangan dan aset daerah kota kotamobagu. Metode yang digunakan adalahdeskriptif. Hasil penelitiannya yaitu pelaksanaan sistem yang dibuat sudah layak digunakan dan prosedur yang ada sudah memadai.

2. Andrew (2013) dengan judul Analisis Penerapan Sistem dan Prosedur Pengeluaran Kas pada Bandan Penanggulangan Bencana Daerah (BPBD) Provinsi Sulawesi Utara. Tujuannya untuk mengetahui penerapan sistem dan prosedur pengeluaran kas pada badan penanggulangan bencana daerah provinsi sulawesi utara sudah sesuai dengan aturan. Metode yang digunakan adalah deskriptif. Hasil penelitiannya yaitu pelaksanaan sistem dan prosedur pengeluaran kas sudah sesuai dengan undang-undang.

\section{METODE PENELITIAN}

\subsection{Data}

Jenis penelitian yang akan dilakukan adalah penelitian deskriptif. Penelitian deskriptif adalah suatu bentuk penelitian yang ditujukan untuk mendeskripsikan fenomena-fenomena yang ada, baik fenomena alamiah maupun fenimena buatan manusia. (Sukmadinata, 2006:72).

Penelitian ini dilaksanakan pada Dinas Kesehatan Kota Manado yang berlokasi di Jalan 17 Agustus Manado. Waktu dilaksanakan pada bulan januari sampai februari 2015, penelitian ini dapat dilaksanakan dengan persetujuan dari pimpinan Dinas Kesehatan Kota Manado. Adapun prosedur penelitian ini yaitu sebagai berikut:

1. Studi Kepustakaan

2. Menentukan Permasalahan

3. Penetapan metode pengumpulan data, observasi, wawancara, dokumen dan diskusi terarah

4. Analisa data selama pelatihan

5. Analisa data setelah validasi dan reliabilitas

6. Hasil dan kesimpulan

Data yang digunakan dalam penelitian ini adalah data kualitatif. Data tersebut yaitu berupa dokumen, formulir, prosedur, informasi tentang pelaksanaan sistem dan prosedur pengeluaran kas di Dinas Kesehatan Kota Manado. Sumber data yang digunakan dalam penelitian ini adalah data primer dan data sekunder. Teknik pengumpulan data dalam penelitian ini sebagai berikut: 
1. Observasi dengan melakukan pengamatan langsung di objek penelitian

2. Teknik wawancara, yang dilakukan melalui tanya jawab dengan pihak-pihak terkait dengan penelitian.

\subsection{Definisi Operasional}

Untuk menghindari kesalahan persepsi maka penulis membuat penjelasan tentang penelitian ini yaitu sistem dan prosedur pengeluaran kas mekanisme Uang Persediaan (UP) adalah uang yang disediakan untuk mengisi tiap-tiap SKPD yang dilakukan setahun sekali. Ganti Uang (GU) adalah uang yang dipergunakan untuk mengganti uang persediaan yang telah terpakai. Tambahan Uang (TU) adalah jika ada pengeluaran yang sedemikian rupa sehingga saldo UP tidak akan cukup untuk membiayainya, maka akan dilakukan tambahan uang ke SKPD. Dana Langsung (LS) adalah pembayaran langsung pada pihak ketiga.

\subsection{Metode Analisis Data}

Metode analisis yang digunakan dalam penelitian ini adalah metode analisis deskriptif yaitu suatu metode yang bertujuan untuk membuat gambaran secara sistematis, faktual dan akrual mengenai fakta-fakta, dengan membandingkan antara sistem-sistem prosedur pengeluaran kas yang dipelajari secara teoritis.

\section{HASIL PENELITIAN DAN PEMBAHASAN \\ 4.1 Hasil Penelitian}

Visi dari Dinas Kesehatan Kota Manado adalah Manado sehat menuju Kota Model Ekowisata. Misi dari Dinas Kesehatan Kota Manado adalah mewujudkan pelayanan kesehatan yang berkualitas dan menyenangkan serta terjangkau oleh seluruh masyarakat, meningkatkan derajat kesehatan masyarakat melalui pemberdayaan masyarakat.

1. Pengajuan Surat Permintaan Pembayaran (SPP-UP)

SPP-UP dipergunakan untuk mengisi uang persediaan (UP) tiap-tiap SKPD. Pengajuan SPP-UP hanya dilakukan sekali dalam setahun. Prosedur pengajuan SPP-UP adalah sebagai berikut.

a. Pengguna anggaran yakni Kepala Dinas Kesehatan menyerahkan SPD kepada Bendahara dan PPK-SKPD

b. Berdasarkan SPD dan SPJ, Bendahara membuat SPP-UP beserta dokumen lainnya yang terdiri dari: Surat pengantar SPP-UP, Ringkasan SPP-UP, Rincian SPP-UP, Salinan SPD, Surat Pernyataan Pengguna Anggaran, Lampiran lain (daftar rincian rencana pengguna dana sampai dengan jenis belanja)

c. Bendahara menyerahkan SPP-UP beserta dokumen lain kepada PPK-SKPD

d. PPK-SKPD meneliti kelengkapan dokumen SPP-UP dan kesesuainnya dengan SPD dan DPA-SKPD

e. SPP-UP yang dinyatakan lengkap akan dibuatkan Rancangan SPM oleh PPK-SKPD. Penerbitan SPM paling lambat 2 hari kerja sejak SPP-UP diterima.

f. Rancangan SPM ini kemudian diberikan PPK-SKPD kepada pengguna anggaran untuk diotorisasi.

g. Jika SPP-UP dinyatakan tidak lengkap, PPK-SKPD akan menerbitkan Surat penolakan SPM. Penolakan SPM paling lambat 1 hari kerja sejak SPP-UP diterima.

h. Surat penolakan penerbitan SPM diberikan kepada Bendahara agar Bendahara melakukan penyempurnaan SPP-UP. Kemudian diserahkan kepada PPK-SKPD untuk diteliti kembali.

2. Penerbitan Surat Perintah Membayar (SPM-UP)

Proses penerbitan SPM adalah tahapan penting dalam penatausahaan pengeluaran yang merupakan tahap lanjutan dari proses pengajuan SPP. Prosedur pengajuan SPM-UP adalah sebagai berikut.

a. Pengguna anggaran yakni Kepala Dinas Kesehatan menyerahkan SPD kepada 


\section{Bendahara dan PPK SKPD}

b. Berdasarkan SPD dan SPJ, Bendahara membuat SPP-GU beserta dokumen lainnya, yang terdiri dari Surat Pengantar SPP-UP, Ringkasan SPP-UP, Rincian SPP-UP, Salinan SPD, Surat Pernyataan Pengguna Anggaran, Lampiran lain (daftar rincian rencana penggunaan dana sampai dengan jenis belanja)

c. Bendahara menyerahkan SPP-UP beserta dokumen lain kepada PPK SKPD

d. PPK SKPD meneliti kelengkapan dokumen SPP-UP dan kesesuaiannya dengan SPD dan DPA-SKPD

e. SPP-UP yang dinyatakan lengkap akan dibuatkan Rancangan SPM oleh PPK SKPD. Penerbitan SPM paling lambat 2 hari kerja sejak SPP-UP diterima

f. Rancangan SPM kemudian diberikan PPK SKPD kepada Pengguna Anggaran untuk diotorisasi

g. Jika SPP-UP dinyatakan tidak lengkap, maka PPK SKPD akan menerbitkan Surat Penolakan Penerbitan SPM. Penolakan SPM paling lambat 1 hari kerja sejak SPP-UP diterima

h. Surat penolakan penerbitan SPM diserahkan kepada Bendahara agar Bendahara melakukan penyempurnaan SPP-GU. Kemudian diserahkan kepada PPK SKPD untuk diteliti kembali.

3. Penerbitan Surat Perintah Pencairan Dana (SP2D-UP)

SP2D atau Surat Perintah Pencairan Dana adalah surat yang dipergunakan untuk mencairkan dana lewat bank yang ditunjuk setelah SPM diterima oleh BUD. Prosedur penerbitan SP2D-UP adalah sebagai berikut.

a. Pengguna anggaran yakni Kepala Dinas Kesehatan menyerahkan SPM kepada kuasa BUD

b. Kuasa BUD meneliti kelengkapan SPM yang diajukan

c. Apabila SPM dinyatakan lengkap, Kuasa BUD menerbitkan SP2D paling lambat 2 hari kerja sejak diterimanya pengajuan SPM

d. SP2D diserahkan kepada Bank dan Pengguna Anggaran

e. Kuasa BUD sendiri harus mencatat SP2D dan Nota Debet (dari bank) pada dokumen penatausahaan, yang terdiri dari Buku Kas Penerimaan, Buku Kas Pengeluaran

f. Pengguna Anggaran menyerahkan SP2D kepada Bendahara Pengeluaran

g. Bendahara mencatat SP2D pada Dokumen Penatausahaan, yang terdiri dari BKU Pengeluaran, Buku Pembantu Panjar, Buku Pembantu Simpanan Bank, Buku Rekapitulasi Pengeluaran, Buku Pembantu Pajak Perincian Objek

h. Apabila SPM dinyatakan tidak lengkap, Kuasa BUD menerbitkan surat penolakan penerbitan SP2D paling lambat 1 hari kerja sejak SPM diterima

i. Surat penolakan penerbitan SP2D ini diserahkan kepada Pengguna Anggaran agar dilakukan penyempurnaan SPM. Kemudian diserahkan kembali kepada Kuasa BUD untuk diteliti.

\section{Prosedur Ganti Uang (GU)}

1. Pengajuan Surat Permintaan Pembayaran (SPP-GU)

SPP-GU digunakan untuk mengganti UP yang sudah terpakai. Prosedur pengajuan SPPGU adalah sebagai berikut.

a. Pengguna Anggaran yakni Kepala Dinas Kesehatan menyerahkan SPD kepada Bendahara dan PPK-SKPD

b. Berdasarkan SPD dan SPJ, Bendahara membuat SPP-UP beserta dokumen lainnya yang terdiri dari Surat Pengantar SPP-GU, Ringkasan SPP-GU, Rincian SPP-GU, Surat Pengesahan SPJ atas penggunaan dana SPP-GU sebelumnya, Salinan SPD, Surat pernyataan pengguna anggaran, Lampiran lain

c. Bendahara menyerahkan SPP-GU beserta dokumen lain kepada PPK-SKPD 
d. PPK-SKPD meneliti kelengkapan dokumen SPP-GU berdasar SPD dan DPA-SKPD

e. SPP-GU yang dinyatakan lengkap akan dibuatkan Rancangan SPM oleh PPK-SKPD. Penerbitan SPM paling lambat 2 hari kerja sejak SPP-GU diterima.

f. Rancangan SPM ini kemudian diberikan PPK-SKPD kepada pengguna anggaran untuk diotorisasi

g. Jika SPP-GU dinyatakan tidak lengkap, PPK-SKPD akan menerbitkan surat penolakan SPM. Penolakan SPM paling lambat 1 hari kerja sejak SPP-GU diterima

h. Surat penolakan penerbitan SPM diberikan kepada Bendahara agar bendahara melakukan penyempurnaan SPP-GU. Kemudian diserahkan kepada PPK-SKPD untuk diteliti kembali.

2. Penerbitan Surat Perintah Membayar (SPM-GU)

Prosedur pengajuan SPM-GU adalah sebagai berikut.

a. Pengguna Anggaran yakni Kepala Dinas Kesehatan menyerahkan SPD kepada PPK SKPD dan Bendahara

b. Berdasarkan SPD dan SPJ, bendahara membuat SPP-GU beserta dokumen lainnya, yang terdiri dari Surat Pengantar SPP-GU, Ringkasan SPP-GU, Rincian SPP-GU, Surat Pengesahan SPJ atas penggunaan dana SPP-GU sebelumnya, Salinan SPD, Surat Pernyataan Penggunaan Anggaran, Lampiran lain

c. Bendahara menyerahkan SPP-GU beserta dokumen lainnya kepada PPK SKPD

d. PPK SKPD meneliti SPP GU berdasar SPD dan DPA-SKPD

e. Apabila SPP-GU dinyatakan lengkap maka PPK SKPD membuat Rancangan SPM, paling lambat 2 hari kerja sejak SPP diterima

f. PPK SKPD menyerahkan SPM kepada Pengguna anggaran untuk diotorisasi

g. Jika SPP-GU dinyatakan tidak lengkap, maka PPK SKPD akan membuat Surat Penolakan Penerbitan SPM, paling lambat 1 hari kerja sejak SPP-GU diterima

h. Surat penolakan penerbitan SPM diberikan kepada Bendahara agar Bendahara melakukan penyempurnaan SPP-GU. Kemudian diserahkan kepada PPK SKPD untuk diteliti kembali.

3. Penerbitan Surat Perintah Pencairan Dana (SP2D-GU)

Proses penerbitan SP2D-GU adalah sebagai berikut.

a. Pengguna Anggaran yakni Kepala Dinas Kesehatan menyerahkan SPM kepada kuasa BUD

b. Kuasa BUD meneliti kelengkapan SPM yang diajukan

c. Apabila SPM dinyatakan tidak lengkap, Kuasa BUD menerbitkan SP2D paling lambat 2 hari kerja sejak diterimanya pengajuan SPM

Kelengkapan dokumen untuk penerbitan SP2D-GU adalah sebagai berikut:

1. Surat pengesahan SPJ Bendahara Pengeluaran periode sebelumnya

2. Ringkasan pengeluaran perincian objek disertai bukti pengeluaran yang sah dan kelengkapan

3. Bukti atas penyetoran $\mathrm{PPN} / \mathrm{PPh}$

d. SP2D diserahkan kepada Bank dan Pengguna Anggaran

e. Kuasa BUD sendiri harus mencatat SP2D dan Nota Debet (dari bank) pada dokumen penatausahaan, yang terdiri dari Buku kas penerimaan, Buku kas pengeluaran

f. Pengguna anggaran menyerahkan SP2D kepada Bendahara

g. Bendahara mencatat SP2D pada Dokumen Penatausahaan, yang terdiri dari BKU Pengeluaran, Buku pembantu simpanan bank, Buku pembantu pajak, Buku pembantu panjar, Buku rekapitulasi pengeluaran perincian objek

h. Apabila SPM dinyatakan tidak lengkap, Kuasa BUD menerbitkan surat penolakan penerbitan SP2D paling lambat 1 hari kerja sejak SPM diterima

i. Surat penolakan penerbitan SP2D ini diserahkan kepada Pengguna anggaran agar 
dilakukan penyempurnaan SPM. Kemudian diserahkan kembali kepada Kuasa BUD untuk diteliti.

\section{Prosedur Tambahan Uang (TU)}

1. Pengajuan Surat Permintaan Pembayaran (SPP-TU)

SPP-TU dipergunakan untuk memintakan tambahan uang, apabila ada pengeluaran yang sedemikian rupa sehingga saldo UP tidak akan cukup untuk membiayainya. Prosedur pengajuan SPP-TU adalah sebagai berikut.

a. Pengguna anggaran yakni Kepala Dinas Kesehatan menyerahkan SPD kepada Bendahara dan PPK-SKPD

b. Berdasarkan SPD dan SPJ, Bendahara membuat SPP-UP beserta dokumen lainnya yang terdiri dari Surat pengantar SPP-TU, Ringkasan SPP-TU, Rincian SPP-TU, Surat pengesahan SPJ atas penggunaan dana SPP-GU sebelumnya, Salinan SPD, Surat keterangan penjelasan keperluan pengisian TU, Lampiran lain

c. Bendahara menyerahkan SPP-TU beserta dokumen lain kepada PPK-SKPD

d. PPK-SKPD meneliti kelengkapan dokumen SPP-TU berdasar SPD dan DPA-SKPD

e. SPP-TU yang dinyatakan lengkap akan dibuatkan rancangan SPM oleh PPK-SKPD. Penerbitan SPM paling lambat 2 hari kerja sejak SPP-TU diterima

f. Rancangan SPM ini kemudian diberikan PPK-SKPD kepada pengguna anggaran untuk diotorisasi

g. Jika SPP-TU dinyatakan tidak lengkap, PPK-SKPD akan menerbitkan surat penolakan SPM. Penolakan SPM paling lambat 1 hari kerja sejak SPP-TU diterima.

h. Surat penolakan penerbitan SPM diberikan kepada Bendahara agar Bendahara melakukan penyempurnaan SPP-TU. Kemudian diserahkan kepada PPK-SKPD untuk diteliti kembali.

2. Penerbitan Surat Permintaan Membayar (SPM-TU)

Prosedur penerbitan SPM-TU adalah sebagai berikut.

a. Pengguna Anggaran yakni Kepala Dinas Kesehatan menyerahkan SPD kepada PPK SKPD dan Bendahara

b. Berdasarkan SPD dan SPJ, bendahara membuat SPP-TU beserta dokumen lainnya, yang terdiri dari Surat Pengantar SPP-TU, Ringkasan SPP-TU, Rincian SPP-TU, Surat Pengesahan SPJ atas penggunaan dana SPP-GU sebelumnya, Salinan SPD, Surat Pernyataan Penggunaan Anggaran, Lampiran lain

c. Bendahara menyerahkan SPP-TU beserta dokumen lainnya kepada PPK SKPD

d. PPK SKPD meneliti SPP-TU berdasar SPD dan DPA-SKPD

e. Apabila SPP-TU dinyatakan lengkap maka PPK SKPD membuat Rancangan SPM, paling lambat 2 hari kerja sejak SPP diterima

f. PPK SKPD menyerahkan SPM kepada Pengguna anggaran untuk diotorisasi

g. Jika SPP-TU dinyatakan tidak lengkap, maka PPK SKPD akan membuat Surat Penolakan Penerbitan SPM, paling lambat 1 hari kerja sejak SPP-TU diterima.

h. Surat penolakan penerbitan SPM diberikan kepada Bendahara agar Bendahara melakukan penyempurnaan SPP-TU. Kemudian diserahkan kepada PPK SKPD untuk diteliti kembali.

3. Penerbitan Surat Perintah Pencairan Dana (SP2D-TU)

Prosedur penerbitan SP2D-TU adalah sebagai berikut.

a. Pengguna Anggaran yakni Kepala Dinas Kesehatan menyerahkan SPM kepada Kuasa BUD

b. Kuasa BUD meneliti kelengkapan SPM yang diajukan

c. Apabila SPM dinyatakan lengkap, Kuasa BUD menerbitkan SP2D paling lambat 2 hari kerja sejak diterimanya pengajuan SPM. Kelengkapan dokumen untuk penerbitan SP2D-TU yaitu surat pernyataan tanggungjawab Pengguna Anggaran/Kuasa Pengguna 
Anggaran

d. SP2D diserahkan kepada Bank dan Pengguna Anggaran

e. Kuasa BUD sendiri harus mencatat SP2D dan Nota Debet (dari Bank) pada dokumen penatausahaan, yang terdiri dari Buku Kas Penerimaan, Buku Kas Pengeluaran

f. Buku Kas Pengeluaran Bendahara mencatat SP2D pada dokumen penatausahaan, yang terdiri dari BKU Pengeluaran, Buku Pembantu Panjar, Buku Pembantu Simpanan Bank

, Buku Rekapitulasi Pengeluaran, Buku Pembantu Pajak Perincian Objek

g. Apabila SPM dinyatakan tidak lengkap, Kuasa BUD menerbitkan surat penolakan penerbitan SP2D paling lambat 1 hari kerja sejak SPM diterima

h. Surat penolakan penerbitan SP2D ini diserahkan kepada Pengguna Anggaran agar dilakukan penyempurnaan SPM. Kemudian diserahkan kembali kepada Kuasa BUD untuk diteliti.

\section{Prosedur Langsung (LS)}

1. Pengajuan Surat Permintaan Pembayaran (SPP-LS)

Prosedur pengajuan SPP-LS adalah sebagai berikut.

a. Pengguna anggaran yakni Kepala Dinas Kesehatan menyerahkan SPD kepada Bendahara dan PPK-SKPD

b. Berdasarkan SPD dan SPJ, Bendahara membuat SPP-UP beserta dokumen lainnya yang terdiri dari Surat pengantar SPP-LS Gaji, Ringkasan SPP-LS Gaji, Rincian SPP-LS Gaji

c. Bendahara menyerahkan SPP-LS Gaji beserta dokumen lain kepada PPK-SKPD

d. PPK-SKPD meneliti kelengkapan dokumen SPP-LS Gaji berdasar SPD dan DPASKPD

e. SPP-LS Gaji yang dinyatakan lengkap akan dibuatkan rancangan SPM oleh PPKSKPD. Penerbitan SPM paling lambat 2 hari sejak SPP-LS Gaji diterima

f. PPK-SKPD menyerahkan SPM kepada pengguna anggaran untuk diotorisasi

g. Jika SPP-LS Gaji dinyatakan tidak lengkap, PPK-SKPD akan menerbitkan Surat Penolakan SPM. Penolakan SPM paling lambat 1 hari kerja sejak SPP-LS Gaji diterima

h. Surat penolakan penerbitan SPM diberikan kepada Bendahara agar Bendahara melakukan penyempurnaan SPP-LS Gaji. Kemudian diserahkan kepada PPK-SKPD untuk diteliti kembali.

2. Penerbitan Surat Perintah Membayar (SPM-LS)

Prosedur penerbitan SPM-LS adalah sebagai berikut.

a. Pengguna Anggaran yakni Kepala Dinas Kesehatan menyerahkan SPD kepada PPK SKPD dan Bendahara

b. Berdasarkan SPD dan SPJ, bendahara membuat SPP-GU beserta dokumen lainnya, yang terdiri dari Surat Pengantar SPP-LS Gaji, Ringkasan SPP-LS Gaji, Rincian SPPLS Gaji

c. Bendahara menyerahkan SPP-LS Gaji beserta dokumen lainnya kepada PPK SKPD

d. PPK SKPD meneliti SPP-LS Gaji berdasar SPD dan DPA-SKPD

e. Apabila SPP-LS Gaji dinyatakan lengkap maka PPK SKPD membuat Rancangan SPM, paling lambat 2 hari kerja sejak SPP diterima

f. PPK SKPD menyerahkan SPM kepada Pengguna anggaran untuk diotorisasi

g. Jika SPP-LS Gaji dinyatakan tidak lengkap, maka PPK SKPD akan membuat Surat Penolakan Penerbitan SPM, paling lambat 1 hari kerja sejak SPP-LS Gaji diterima

h. Surat penolakan penerbitan SPM diberikan kepada Bendahara agar Bendahara melakukan penyempurnaan SPP-LS Gaji. Kemudian diserahkan kepada PPK SKPD untuk diteliti kembali.

\subsection{Pembahasan}

\section{Prosedur Uang Persediaan (UP)}

Pengajuan Uang Persediaan (UP) hanya dilakukan setahun sekali oleh Dinas 
Kesehatan Kota Manado, selanjutnya untuk mengisi saldo UP akan menggunakan SPP-GU. Mekanisme ini sudah sesuai dengan Permendagri No. 13 Tahun 2006 dengan perubahannya No. 59 Tahun 2007 Tentang Pedoman pengelolaan Keuangan Daerah tentang Pedoman Sistem dan Prosedur Penatausahaan dan Akuntansi, Pelaporan dan Pertanggungjawaban Keuangan Daerah dan SE 900/316/BAKD tentang Pedoman Sistem dan Prosedur Penatausahaan dan Akuntansi, Pelaporan dan Pertanggungjawaban Keuangan Daerah. Namun dalam pelaksanaannya pengajuan dokumen SPP-UP yang dilakukan bendahara pengeluaran tanpa melalui otorisasi PPK-SKPD.

\section{Prosedur Ganti Uang (GU)}

Ganti Uang (GU) digunakan untuk mengganti UP yang telah terpakai, dimana UP tersebut dipertanggungjawabkan penggunaan uang. Mekanisme ini diajukan oleh Dinas Kesehatan Kota Manado ketika UP habis. Proses penerbitan GU sudah sejalan dengan Permendagri No.13 Tahun 2006 dengan perubahannya No.59 Tahun 2007 tentang Pedoman Pengelolaan Keuangan Daerah dan SE 900/316/BAKD tentang Pedoman Sistem dan Prosedur Penatausahaan dan Akuntansi, Pelaporan dan Pertanggungjawaban Keuangan Daerah. Namun dalam pelaksanaannya pengajuan dokumen SPP-GU yang dilakukan bendahara pengeluaran tanpa melalui otorisasi PPK-SKPD.

\section{Prosedur Tambahan Uang (TU)}

Mekanisme ini hanya dipergunakan oleh Dinas Kesehatan Kota Manado untuk memintakan tambahan uang, apabila terjadi pengeluaran yang sedemikian rupa sehingga saldo UP tidak akan cukup untuk membiayainya. Proses ini sudah sesuai dengan Permendagri No. 13 Tahun 2006 dengan perubahannya No. 59 Tahun 2007 Tentang Pedoman Pengelolaan Keuangan Daerah dan SE 900/316/BAKD tentang Pedoman Sistem dan Prosedur Penatausahaan dan Akuntansi, Pelaporan dan Pertanggungjawaban Keuangan Daerah. Namun dalam pelaksanaannya pengajuan dokumen SPP-TU yang dilakukan bendahara pengeluaran tanpa melalui otorisasi PPK-SKPD.

\section{Prosedur Langsung (LS)}

Surat Permintaan Pembayaran Langsung (SPP-LS) digunakan untuk pembayaran langsung pada pihak ketiga dengan jumlah yang telah ditetapkan. Proses penerbitan LS sudah sesuai dengan Permendagri No. 13 Tahun 2006 dengan perubahannya No.59 Tahun 2007 tentang Pedoman Pengelolaan Keuangan Daerah dan SE 900/316/BAKD tentang Pedoman Sistem dan Prosedur Penatausahaan dan Akuntansi, Pelaporan dan Pertanggungjawaban Keuangan Daerah. Namun dalam pelaksanaannya pengajuan dokumen SPP-LS yang dilakukan bendahara pengeluaran tanpa melalui otorisasi PPK-SKPD.

\section{KESIMPULAN}

Berdasarkan hasil penelitian dan pembahasan yang dilakukan di Dinas Kesehatan Kota Manado maka dapat diambil kesimpulan yaitu, prosedur sistem dan prosedur pengeluaran kas belanja Uang Persediaan (UP)/Ganti Uang (GU)/Tambah Uang (TU)/Langsung (LS) pada Dinas Kesehatan Kota Manado sudah efektif dan sesuai peraturan yang berlaku yakni Permendagri No.13 Tahun 2006 dengan perubahannya No.59 Tahun 2007 namun dalam pelaksanaannya masih terdapat kekurangan yaitu dalam proses pengajuan SPP(UP-GU-TU-LS) tanpa otorisasi PPK-SKPD.

Adapun saran yang dapat diberikan oleh penulis yaitu, Prosedur pengeluaran kas pada Dinas Kesehatan Kota Manado sudah sesuai dengan peraturan yang berlaku dan harus menyesuaikan dengan aturan yang ada jika terjadi perubahan peraturan. Dalam pelaksanaan pengeluaran kas Dinas Kesehatan Kota Manado harus dilakukan sesuai dengan peraturan yang berlaku yakni harus ada otorisasi dari PPK-SKPD untuk proses pengajuan SPP (UP-GUTU-LS). Pengeluaran kas pada Dinas Kesehatan Kota Manado memberikan manfaat yang benar-benar dapat dirasakan oleh masyarakat. 


\section{DAFTAR PUSTAKA}

Bastian, Indra (2009), Akuntansi Sektor Publik, Erlangga, Jakarta.

Halim, Abdul (2008), Sistem Akuntansi Sektor Publik, STIE YKPS, Yogyakarta.

Mardiasmo (2009), Akuntansi Sektor Publik, Andi, Yogyakarta.

Mahmudi (2011), Akuntansi sektor Publik, UII Pres, Yogyakarta.

Paputungan, Revalina (2011), Analisis Pelaksanaan Sistem dan Prosedur Penerimaan Pengeluaran Kas pada Dinas Pendapatan Pengelolaan Keuangan dan Aset Daerah Kotamobagu, Skripsi Fakultas Ekonomi, Universitas Sam Ratulangi, Manado.

Republik Indonesia, Peraturan Menteri Dalam Negeri No. 13 Tahun 2006 Tentang pedoman pengelolaan keuangan daerah, Jakarta.

Republik Indonesia, Peraturan Menteri Dalam Negeri No. 55 Tahun 2008 tentang tata cara penatausahaan dan penyusunan laporan pertanggungjawaban bendahara serta penyampaiannya, Jakarta.

Republik Indonesia, Peraturan Menteri Dalam Negeri No. 59 Tahun 2007 Tentang Perubahan Atas Peraturan Pemerintah Dalam Negeri No. 13 Tahun 2006 Tentang Pedoman Pengelolaan Keuangan Daerah, Jakarta.

Republik Indonesia, Peraturan Pemerintah No. 71 Tahun 2010 Tentang Standar Akuntansi Pemerintahan, Jakarta.

Republik Indonesia, Peraturan Pemerintah No. 58 Tahun 2005 Tentang Pengelolaan Keuangan Daerah, Jakarta.

Republik Indonesia, Peraturan Pemerintah No. 60 Tahun 2008 Tentang Sistem Pengendalian Internal, Jakarta.

Republik Indonesia, Undang-Undang No. 32 Tahun 2004 tentang Pemerintahan Daerah, Jakarta.

Republik Indonesia, Undang-Undang No. 33 Tahun 2004 tentang Perimbangan Keuangan Pemerintah Pusat dan Pemerintah Daerah, Jakarta.

Saputra, Andrew (2013), Analisis Penerapan Sistem dan Prosedur Pengeluaran Kas pada Badan Penanggulangan Bencana Daerah Provinsi Sulawesi Utara, Skripsi Fakultas Ekonomi, Universitas Sam Ratulangi.

Supit, Chicilia (2012), Analisis Pengakuan, Pengukuran, Dan Pelaporan Keuangan Dinas Kesehatan Kota Manado, Skripsi Fakultas Ekonomi, Universitas Sam Ratulangi, Manado.

Surat Edaran 900/316/BAKD Tentang Pedoman Sistem dan Prosedur Penatausahaan dan Akuntansi, Pelaporan dan Pertanggungjawaban Keuangan Daerah, Jakarta.

Weygandt Jerry, Kieso E Donald dan Kimmel D Paul (2007), Pengantar Akuntansi Buku I, Edisi Tujuh, Alih Bahasa oleh Ali Akbar Yulianto, Wasifah, Rangga Handika, Salemba Empat, Jakarta 